\title{
Microwave Drying of Wastewater Sewage Sludge
}

\author{
Zhenyu Chen, Muhammad T. Afzal, and Arshad Adam Salema
}

\begin{abstract}
The purpose of this study was to investigate the effect of Microwave (MW) power levels (480 to $1080 \mathrm{~W})$ and sample mass $(90$ to $150 \mathrm{~g}$ ) on the drying characteristics of the sewage sludge. The drying tests were carried out using a modified domestic microwave unit with a process control system. The results showed that drying rate was directly proportional to the MW power, but inversely proportional to the sample mass. The desired temperature could be achieved in short period of time at higher power level. MW drying showed a significant increase (from $5.65 \mathrm{MJ} / \mathrm{kg}$ to $18.75 \mathrm{MJ} / \mathrm{kg}$ ) in calorific value of sewage sludge.
\end{abstract}

Index Terms-Calorific value, kinetics, microwave drying, sewage sludge.

\section{INTRODUCTION}

More recently, due to increased awareness, environment has become an integral component of sustainability, which implies not only to ecology, but also to economic and social development. One of the most challenging issues in wastewater management is handling of sewage sludge. The production of biosolids ranges from 20 to $32.85 \mathrm{~kg}$ (dry basis, d.b.) per person per year. Canada produces more than 6.6 million tons (d.b.) of biosolids annually [1]-[2]. High moisture, complex constituents and characteristics are the difficulties faced in handling and management of wastewater sewage sludge. In fact, the cost, which includes treatment, transportation and disposal of sewage sludge currently, represents about 50 to $60 \%$ of total exploitation costs. Consequently, the increasing production of sewage sludge has become a considerable problem.

Drying process cannot only solve the handling problem of sewage sludge but can also make it as a value added products. Mechanical dewatering can only reduce moisture content of sewage sludge to around $70 \%$, while drying can reduce it to less than $10 \%$ [3]. This could cut the cost of transportation by reducing the large volume and weight of the material. Besides this, drying also improves the combustion performance by increasing the calorific value of the sludge. The calorific value of dried sewage sludge is almost equal to that of brown coal [4].

Thermal drying technique has been applied in advanced wastewater treatment plant (WWTP) for years [5]. Drying is an energy intensive process, and research in improving the energy efficiency is imperative. Study on the parameters such as moisture content, drying rate will help to improve dryer design, drying operation and schedules. Experiments on

Manuscript received June 10, 2013; revised July 29, 2013.

Z. Chen, M. T. Afzal, and A. A. Salema are with the Mechanical Engineering Department, University of New Brunswick, Fredericton, NB, E3B5A3Canada (e-mail: zhenyu.chen@unb.ca, mafzal@unb.ca, arshad.salema@unb.ca). conventional sludge dryers have been reported which works on conduction and convection type of mechanism. For instance, an isothermal drying characteristics of sludge was done in a thermogravimetric analyzer (TGA) [6]. They concluded that the increase of temperature resulted in an increased drying rate, which ultimately decreased the drying time. Further, the time required for complete drying increases as the initial sample mass increases due to the increase in amount of moisture content. Equilibrium moisture content (EMC) of sludge was studied [7] in order to prevent technical problems in dryer design such as over drying, energy loss, etc. A study on drying kinetics of sewage sludge using indirect agitated dryer was reported in [8]. A non-thermal effect was reported during MW drying of sewage sludge [9]. The drying was performed in a convective dryer after MW pre-treatment, and result showed about 30\% reduction in drying time compared with untreated sample.

Conventional thermal drying methods usually give lower drying efficiency and product quality in comparison with Microwave Drying (MWD). MWD offers rapid and selective heating, which gives advanced energy efficiency, enhanced product yield and quality. Thus, microwave (MW) irradiation has gained widespread popularity as an effective thermal method for sludge treatment [10]. However, there still exists research gap in terms of optimizing the drying process condition for the sewage sludge materials. It should be noted that material temperatures are depended on the precise control of the power level. The study on the effect of microwave power and sample mass on the drying characteristics of sewage sludge was found to be very limited in the literature.

Thus, the aim of this study was to investigate the effect of microwave power levels and sample mass on drying characteristics of the sewage sludge. The real time and temperature data was recorded during each test run. Further, attention was also paid to the quality of sewage sludge in terms of calorific value.

\section{MATERIALS AND METHODS}

\section{A. Sample Preparation}

Sewage sludge samples were collected after mechanical dewatering from Wastewater Treatment Plant (WWTP), Fredericton, New Brunswick, Canada. Sludge samples were stored in a refrigerator at $4{ }^{\circ} \mathrm{C}$ and retrieved to room temperature prior to the experiments. An aluminum tube mould of $5.4 \mathrm{~cm}$ diameter, and $7.3 \mathrm{~cm}$ height was used to shape the sludge into cylindrical form before MWD. Fluctuation of sample mass was controlled within $\pm 0.05 \mathrm{~g}$. The initial moisture content (IMC) dry basis was measured by the oven drying as per ASTM D4442-07 method. For this, 
$5 \mathrm{~g}$ of raw material was dried at $105^{\circ} \mathrm{C}$ in an oven for $24 \mathrm{~h}$. The IMC of oven dried sample was calculated as below:

TABLE I: Proximate And Ultimate ANALysis of Sewage SLudge (\%)

\begin{tabular}{|l|c|}
\hline Moisture content & 73.21 \\
\hline Ash & 4.02 \\
\hline Volatile matter & 22.52 \\
\hline Fixed carbon & 0.26 \\
\hline $\mathrm{C}$ & 13.18 \\
\hline $\mathrm{H}$ & 9.84 \\
\hline $\mathrm{N}$ & 1.15 \\
\hline $\mathrm{S}$ & 0.48 \\
\hline $\mathrm{O}$ & 71.34 \\
\hline Calorific value $(\mathrm{MJ} / \mathrm{kg})$, on wet basis & 5.65 \\
\hline
\end{tabular}

$$
I M C=\frac{m_{o}-m_{d}}{m_{d}}
$$

where $\mathrm{m}_{\mathrm{o}}(\mathrm{kg})$ is the initial mass of the sample, $m_{d}(\mathrm{~kg})$ is the mass of oven dried sample. By this method, the IMC of sewage sludge was measured to be $73.2 \%$. The proximate and ultimate analysis of sewage sludge is given in Table I. Low calorific value of sludge was due to high moisture content.

\section{B. Experimental Setup and Procedure}

Microwave Work Station (MWS) unit developed by FISO Technologies Inc. Quebec, Canada was used to perform drying experiments. The MWS is a modified domestic microwave oven with a control system. MW was operated by setting the parameters via FISO acquisition system, which was linked to personal computer via RS-232 port. Real time temperature data was recorded through this system. Temperature of the material was detected by optic fiber sensors with a precision of $\pm 1^{\circ} \mathrm{C}$ and had a range from $-40^{\circ} \mathrm{C}$ to $300^{\circ} \mathrm{C}$. In order to measure the weight loss of the sample an electronic balance with an accuracy of $0.01 \mathrm{~g}$ was placed at the bottom of the MW oven and connected with sample plate inside the oven. Real time weight change was recorded via Windmill data acquisition software.

Three MW power levels, 480, 840, and $1080 \mathrm{~W}$ were used in this study. Sample mass was varied, 90, 120, and $150 \mathrm{~g}$ for each experiment. Experiments were conducted in triplicate for the reliability of data. It should be noted that temperature of sample was kept below $140{ }^{\circ} \mathrm{C}$ to prevent combustion of organic matter. Drying experiments were stopped when the sample mass dropped below the pre-calculated sample mass with moisture content of 0.1 ( $\mathrm{kg} / \mathrm{kg}$ d.b.). Moisture content, moisture ratio and drying rate were calculated from experiment data by using following equations:

$$
\begin{aligned}
& M C=\frac{m_{t}-m_{d}}{m_{d}} \\
& M R=\frac{M_{t}-M_{e}}{M_{0}-M_{e}} \\
& D R=\frac{M_{t+d t}-M_{t}}{d t}
\end{aligned}
$$

where $M C(d . b)$ is the moisture content, $m_{t}$ is the sample mass (g) at a specific time, $m_{d}$ is the total mass of dry solids in the sample $(\mathrm{g}), M R$ is the moisture ratio, $M_{t}(\mathrm{~kg} / \mathrm{kg}$ d.b.) is the moisture content at a specific time, $\mathrm{M}_{0}(\mathrm{~kg} / \mathrm{kg}$ d.b.) is the initial moisture content, $M_{e}(\mathrm{~kg} / \mathrm{kg}$ d.b.) is the equilibrium moisture content and was assumed to be zero for MWD as stated by Maskan [11], $D R(\mathrm{~kg} / \mathrm{kg}$ d.b.min) is the drying rate, $M_{t+d t}(\mathrm{~kg} / \mathrm{kg} \mathrm{d}$.b.) is the moisture content at $t+d t$, and $t(\mathrm{~s})$ is drying time.

\section{Calorific Value}

The calorific value of original and dried sewage sludge was determined by using Parr 1271 oxygen bomb calorimeter at CENNATEK Bioanalytical Services, Ontario, Canada.

\section{RESULTS AND DISCUSSION}

\section{A. Effect of Microwave Power on Drying Kinetics}

Microwave power levels of 480, 840, and $1080 \mathrm{~W}$ were used to dry the sludge sample with a constant mass of $120 \mathrm{~g}$. The loss in moisture content from sludge against the drying time at different MW power levels is shown in Fig. 1. As the MW power level was increased, there was significant decrease in drying time of the sludge. In order to reduce the moisture content of the sludge from 2.73 to $0.1 \mathrm{~kg} / \mathrm{kg}$ d.b., MW power of $1080 \mathrm{~W}, 840 \mathrm{~W}$, and $480 \mathrm{~W}$ took about 7.5 , 9.7, and $19 \mathrm{~min}$, respectively. Thus, the drying time was shortened by about $60 \%$ when the microwave power was increased by $125 \%$ (from $480 \mathrm{~W}$ to $1080 \mathrm{~W}$ ). In a very recent study [12], MW power of $900 \mathrm{~W}, 720 \mathrm{~W}$ and $540 \mathrm{~W}$ took around 11,13 , and $15 \mathrm{~min}$, respectively to dry the sludge,. Similarly, about $46 \%$ decrease in drying time of food products with increase in $14.7 \%$ of MW power was found in [13]. In an another study [14], MW took about 40, 56, and 80 $\mathrm{s}$ to decrease the moisture content of sewage sludge from 80 to $56 \%$, which was much less than the convective drying method. Keeping the initial moisture content of the sludge as similar, the saving in drying time was mainly influenced due to the change in applied MW power.

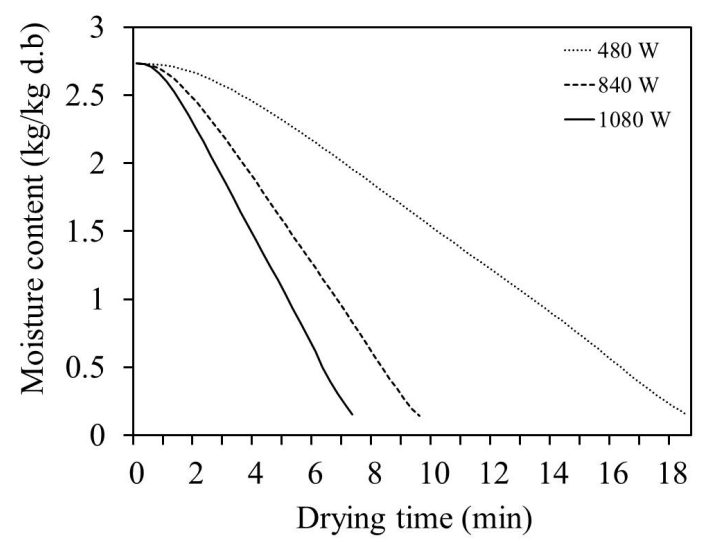

Fig. 1. Moisture loss from sludge at various MW power levels (sample mass $120 \mathrm{~g})$

Much higher heating rate can be achieved at higher MW power levels. This can assists to augment the heat transfer rate within the sludge material resulting in less drying time. The dipole rotation of water molecules in the sample might increase with MW power which can superheat the water in 
fraction of seconds under MW irradiation. The moisture content of the sewage sludge was decreased by $96 \%$ in the present study. Menendez [15] reported about $92 \%$ reduction in volume of sewage sludge after drying in MW compared to $89 \%$ by conventional drying. Significant reduction in sewage sludge volume might bring economic benefit for its further processing. It is assumed that $\mathrm{MW}$ is able to remove the capillary moisture as well as the particle's surface moisture [16].

The MW drying rate curves for the sludge are shown in Fig. 2. Drying rates at constant rate period ranged from 0.08 to 0.20 ( $\mathrm{kg} / \mathrm{kg}$ d.b.min) for the microwave power levels of 480 and $1080 \mathrm{~W}$, respectively. Typically, the drying rates were directly proportional to the microwave power. Consequently, the time during constant rate period decreased as MW power level was increased. In drying of sludge samples, a constant rate period is controlled by external heat transfer followed by a falling rate period in which internal liquid diffusion controls throughout [17]. The moisture content dropped from 0.5 to $0.1 \mathrm{~kg} / \mathrm{kg}$ d.b during the falling rate period. The drying rate was observed to remain almost constant over a long period during MW drying of sludge. The critical moisture content of sewage sludge from Fig. 2 was about $0.6 \mathrm{~kg} / \mathrm{kg}$ d.b., which was in agreement with the literature [17].

Temperature profiles of MWD of sewage sludge for different power levels are presented in Fig. 3. The time taken by the sludge to reach the boiling point of water from room temperature was $2 \mathrm{~min}$ for $480 \mathrm{~W}$ and about $1.2 \mathrm{~min}$ for 840 $\mathrm{W}$ and $1080 \mathrm{~W}$. The rapid increase in temperature was due to the presence of moisture in the sludge samples. Since water is the major component in the sewage sludge in form of moisture, the initial rise in temperature was due to good microwave absorbing property of water. After reaching $100{ }^{\circ} \mathrm{C}$, the temperature profile became plateau. However, the temperature increased sharply from $100{ }^{\circ} \mathrm{C}$ after 5,7 , and $15 \mathrm{~min}$ for 1080,840 , and $480 \mathrm{~W}$, respectively.

The dried sludge shows high oxygenated and aliphatic hydrogen compounds [18]. This might cause slight combustion of organic matter present in the dried sewage sludge leading to sharp rise in the temperature after $100{ }^{\circ} \mathrm{C}$. Temperature in range of 70 to $200{ }^{\circ} \mathrm{C}$ is considered to be drying zone for sewage sludge [13]. Menendez and Inguanzo [19] also found similar temperature profile for sewage sludge under microwave irradiation.

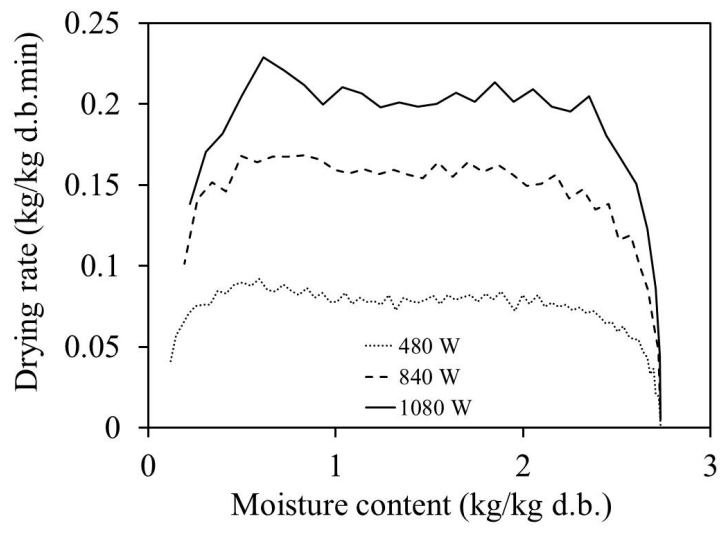

Fig. 2. Drying rate of sludge at various MW power levels (sample mass - 120 g)

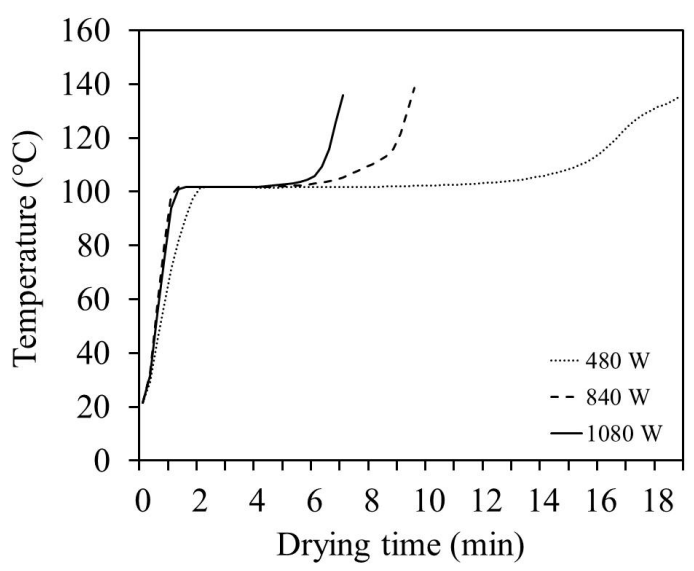

Fig. 3. Temperature profile of sludge drying at various MW power levels (sample mass - $120 \mathrm{~g}$ )

\section{B. Effect of Sample Mass on Drying Kinetics}

Fig. 4 depicts the loss in moisture content of the sludge for different sample mass but at constant MW power level of 840 W. Apparently, large sample size took more time to dry. The drying time increased by about $60 \%$ when the sample mass was increased from $90 \mathrm{~g}$ to $150 \mathrm{~g}$. Hence, the sample amount also plays an important role in determining the time in a MW dryer.

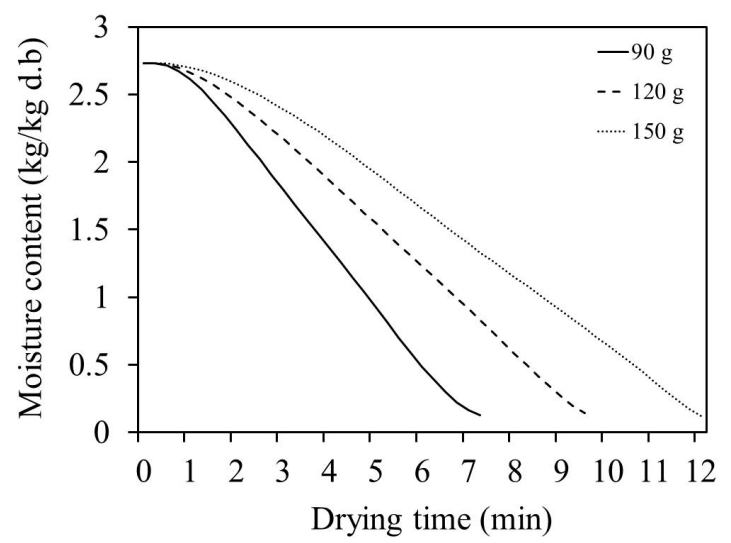

Fig. 4. Moisture loss from sludge at various sample mass (MW power - 840 W)

The drying rate profiles for sewage sludge for different sample mass are given in Fig. 5. At constant rate period, average drying rates of different drying conditions ranged from 0.22 to 0.125 ( $\mathrm{kg} / \mathrm{kg}$ d.b.min) depending on the drying conditions. Rapid increase in drying rate at the initial stage (moisture content between 2.7 to $2.5 \mathrm{~kg} / \mathrm{kg}$ ) was due to absorption of high amount of MW energy by the water present in the sewage sludge in the form of moisture. Low mass of sample gets dried much faster due to transfer of high energy to the material and lower moisture content compared to large samples. Once all the moisture or water is evaporated from the sample, the drying rate starts to drop. This is because the loss of moisture content from the sample cause decrease in the absorption of MW energy by the sample. The internal liquid diffusion mechanism is expected to control the drying rate at the later stage of drying. The moisture content changed from $0.7,0.5,0.35 \mathrm{~kg} / \mathrm{kg}$ d.b. to $0.1 \mathrm{~kg} / \mathrm{kg}$ d.b. for sludge samples of $90,120,150 \mathrm{~g}$, respectively. 


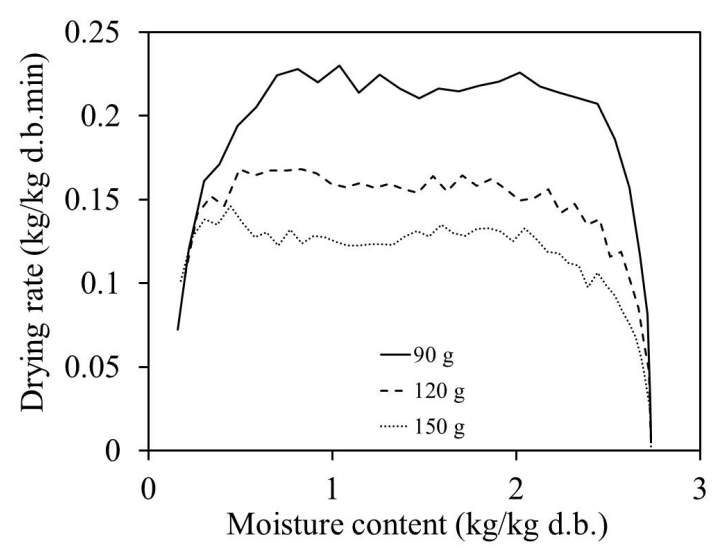

Fig. 5. Drying rate of sludge versus moisture content at various sample mass (MW power - $840 \mathrm{~W}$ )

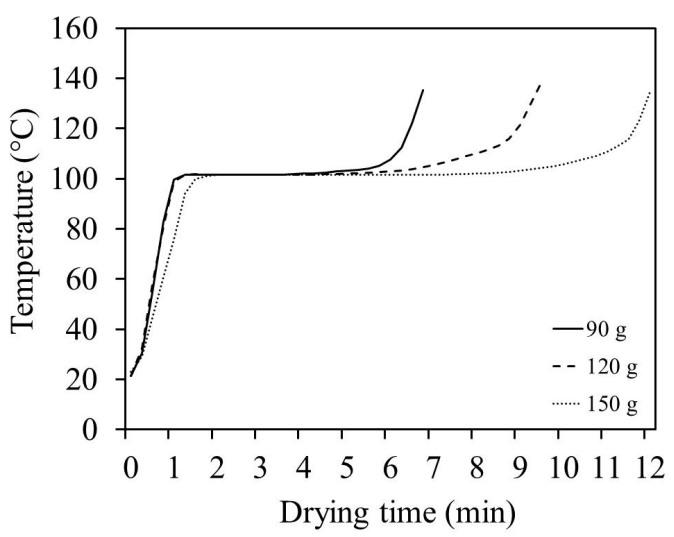

Fig. 6. Temperature profile of sludge MWD at various sample mass (MW power $-840 \mathrm{~W}$ )

Temperature profile for different mass of sewage sludge under MW irradiation is shown in Fig. 6. The temperature profiles were almost similar to that of obtained at different power levels (Fig. 3). The time period increased according to the mass of the sample. Hence, the time to dry $90 \mathrm{~g}$ sample was about half of $150 \mathrm{~g}$ sludge sample. High temperature (> $150{ }^{\circ} \mathrm{C}$ ) was avoided in the present study since this can result in the sintering and burning of sewage sludge [20].

Overall, MWD is a good method to improve the quality and recover resources from sewage sludge waste materials in a safe way [10]. Manara and Zabaniotou [16] reported that MW treatment is more efficient and saves time and energy (power) compared to other technologies. For instance, the drying time for $\mathrm{MW}$ is in few minutes or seconds compared to conventional method which takes nearly hours [14] and days for solar [21] and enhanced convective [22] drying method. However, for high moisture content materials like sewage sludge, nonthermal effect of MW can play a role in the drying process [13]. Moreover, the temperature profiles (Fig. 3 and 6) are dependent on the applied MW power and the sample mass. In other words, larger MW energies require shorter contact time for the irradiation to generate maximum dewaterability [23]. The effects of MW power and respective temperature on the drying kinetics were in agreement with other study [9].

\section{Calorific Value of Sewage Sludge}

Dried domestic sewage sludge can be a potential alternative fuel for heating and energy applications. However, this depends on the calorific value of the sewage sludge. Table II shows the calorific analysis of MW dried sludge samples.

TABLE II: CALORIFIC ANALysis of Mw Dried SEwage Sludge, MJ/KG

\begin{tabular}{|l|c|c|c|}
\hline & $\begin{array}{c}\text { Original } \\
\text { sample }\end{array}$ & Bone dry & $\begin{array}{c}\text { Bone dry and } \\
\text { ash free }\end{array}$ \\
\hline Before MWD & 5.65 & 21.10 & 24.85 \\
\hline After MWD & 18.75 & 20.58 & 23.99 \\
\hline
\end{tabular}

The increase in calorific value by 3 fold as compared to original sample was due to removal of large amount of moisture content. The calorific value of present sewage sludge was comparable to that of air dried lignite coal [24] and higher than dried sewage sludge [25]. The calorific value of bone dried sludge samples decreased slightly after MWD. However, about $97.5 \%$ and $96.5 \%$ of the calorific value still retained in the bone dried sludge cake with and without ash respectively even after MWD. This reduction in calorific value for bone dried sludge could be due to burning out of some organic matter in form of volatile matter.

\section{CONCLUSION}

Using MW irradiation technology can significantly reduce the drying time of the sewage sludge. Intermediate MW power level and sample mass can be efficient in drying the sewage sludge. Drying rate increased rapidly at initial stage of MWD due to high rate of absorption of MW energy by the sludge. After the loss of moisture from the sludge, the absorption of MW energy decreased resulting in a fall of drying rate. Hence, the drying characteristics are greatly depended on the moisture content of the sewage sludge. Furthermore, application of MWD in sewage sludge showed encouraging results in recovering the calorific value. This suggests that sewage sludge can be used as potential alternative fuel in various energy applications.

\section{ACKNOWLEDGMENT}

The authors would like to express their appreciation and thanks to NSERC, NBIF, FAPCC and NBSCIA to support this study. Special thanks also to FAPCC for providing site to carry the experiments.

\section{REFERENCES}

[1] A. Gomez, J. Zubizarreta, M. Rodrigues, C. Dopazo, and N. Fueyo, "Potential and cost of electricity generation from human and animal waste in Spain," Renewable Energy, vol. 35, pp. 498-505, 2010.

[2] CCME. (September 2010). A Review of the Current Canadian Legislative Framework for Wastewater Biosolids. [Online]. PN1446. Available:

http://www.ccme.ca/assets/pdf/pn_1446_biosolids_leg_review_eng.p df.

[3] A. Flaga, "Sludge drying," Polish-Swedish-Ukrainian Seminar Research and Application of New Technologies in Wastewater Treatment and Municipal Solid Waste Disposal in Ukraine, Sweden and Poland, Ukraine, 2006, pp. 73-82,

[4] G. Tchobanoglous, F. L. Burton and H. D. Stensel, Wastewater engineering-treatment, disposal and reuse; New York: McGraw Hill, 1991.

[5] USEPA. (September 2006). Biosolids technology fact sheet: heat drying. USEPA Office of Water. [Online]. Available: http://water.epa.gov/scitech/wastetech/upload/2006_10_16_mtb_heatdrying.pdf 
[6] J. Qian, Y. W. Yoon, P. S. Youn, J. H. Kim, D. S. Choi, J. H. Choi, Y. C. Choi, and B. Jung, "Drying characteristics of sewage sludge," Korean Journal of Chemical Engineering, vol. 28, no. 7, pp. 1636-1640, 2011.

[7] S. R. Bellur, C. J. Coronella, and V. R. Vasquez, "Analysis of biosolids equilibrium moisture and drying," Environmental Progress and Sustainable Energy, vol. 28, no. 2, pp. 291-298, 2009.

[8] J. H. Ferrasse, P. Arlabosse, and D. Lecomte, "Heat, momentum, and mass transfer measurements in indirect agitated sludge dryer," Drying Technology, vol. 20, no. 4-5, pp. 749-769, 2002.

[9] H. X. Huang, H. P. Chen, Z. F. Hu, and X. Q. Ma, "Study on microwave-induced thin-layer drying of municipal sludge for fuel reclamation," Journal of Coal Science and Engineering, vol. 18, no. 3, pp. 307-312, 2012.

[10] V. K. Tyagi and S. L. Lo, "Microwave irradiation: a sustainable way for sludge treatment and resource recovery," Renewable and Sustainable Energy Reviews, vol. 18, pp. 288-305, 2013.

[11] M. Maskan, "Microwave/air and microwave finish drying of banana," Journal of Food Engineering, vol. 44, no. 2, pp. 71-78, 2000.

[12] L. Fang, S. Li, T. Zhai, X. Zhao, and H. A. Sun, "Comparative study on the drying process of sewage sludge: microwave and air-blast," WIT Transactions on the Built Environment, vol. 140, pp. 575-581, 2013.

[13] Z. Kurják, A. Barhács, and J. Beke, "Energetic analysis of drying biological materials with high moisture content by using microwave energy," Drying Technology, vol. 30, no. 3, pp. 312-319, 2012.

[14] W. Zhonghua, W. Long, L. Zhanyong, and A. S. Mujumdar, "Atomization and drying characteristics of sewage sludge inside a Helmholtz pulse combustor," Drying Technology, vol. 30, no. 10, pp. 1105-1112, 2012.

[15] J. A. Menendez, A. Dominguez, M. Inguanzo, and J. J. Pis, "Microwave-induced drying, pyrolysis and gasification (MWDPG) of sewage sludge: Vitrification of the solid residue," Journal of Analytical and Applied Pyrolysis, vol.74, no. 1, pp. 406-412, 2005.

[16] P. Manara, and A. Zabaniotou, "Towards sewage sludge based biofuels via thermochemical conversion-a review," Renewable and Sustainable Energy Reviews, vol. 16, no. 5, pp. 2566-2582, 2012.

[17] A. S. Mujumdar, and S. Devahastin, "Fundamental principles of drying," in Mujumdar's Practical Guide to Industrial Drying, S. Devahastin, Ed. Montreal, QC:Exergex Corp, 2000, ch. 1, pp. 1-22.

[18] A. Dominguez, J. A. Menendez, M. Inguanzo, and J. J. Pis, "Sewage sludge drying using microwave energy and characterization by IRTF," Afinidad, vol. 61, no. 512, pp. 280-285, 2004.

[19] J. A. Menendez and M. Inguanzo, "Microwave-induced Pyrolysis of Sewage Sludge," Water Research, vol. 36, pp. 3261-3264, 2002.

[20] M. Dańczuk, and J. Łomotowski, "Application of microwave energy to the hygienization of sewage sludge," Environment Protection Engineering, vol. 36, no. 4, pp. 77-86, 2010.

[21] V. L. Mathioudakis, A. G. Kapagiannidis, E. Athanasoulia, A. D. Paltzoglou, P. Melidis, and A. Aivasidis, "Sewage Sludge Solar Drying: Experiences from the First Pilot-Scale Application in Greece," Drying Technology, vol. 31, no. 5, pp. 519-526, 2013.

[22] R. Han, J. Liu, Y. Zhang, X. Fan, W. Lu, and H. Wang, "Dewatering and granulation of sewage sludge by biophysical drying and thermo-degradation performance of prepared sludge particles during succedent fast pyrolysis," Bioresource Technology, vol. 107, pp. 429-436, 2012.

[23] Q. Yu, H. Lei, G. Yu, X. Feng, Z. Li, and Z. Wu, "Influence of microwave irradiation on sludge dewaterability," Chemical Engineering Journal, vol. 155, no. 1, pp. 88-93, 2009.

[24] M. Karthikeyan, "Minimization of moisture readsorption in dried coal samples," Drying Technology, vol. 26, no. 7, pp. 948-955, 2008.
[25] A. Domínguez, J. A. Menéndez, M. Inguanzo, and J. J. Pis, "Production of bio-fuels by high temperature pyrolysis of sewage sludge using conventional and microwave heating," Bioresource Technology, vol. 97, no. 10, pp. 1185-1193, 2006.

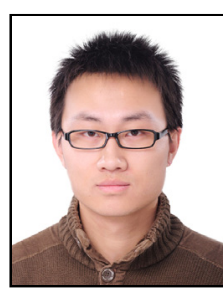

Zhenyu Chen graduated as mechanical engineer from East China University of Science and Technology, China in 2010. Currently he is pursuing his Master's degree in Mechanical Engineering at the University of New Brunswick, Canada.

He worked as research assistant for Wolfberry Research Institute, Ningxia Academy of Agriculture and Forestry Sciences on the project of wolfberry harvester during undergraduate study. He has also two patents under his name in wolfberry harvester. His research interes includes renewable energy, drying technology, microwave technology, biosolids processing, and machine design.

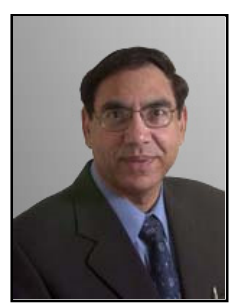

Muhammad T. Afzal graduated in Agricultural Engineering from University of Agriculture Faisalabad, Pakistan in 1982. He obtained his Master's degree in Food Process Engineering (post-harvest technology) from Asian Institute of Technology (AIT), Thailand in 1987 and $\mathrm{PhD}$ from Department of Biomechanical Systems, Ehime University, Japan in 1999. He has more than 25 years of experience in research and teaching.

He has published more than 60 papers, reports and technical articles and made presentations at several international conferences. His research interests include feedstock engineering, biomass pretreatment and processing to value-added products, solid biofuels, bioproducts and biomaterials, microwave technology, heat and mass transfer, drying, renewable energy, life cycle analysis.

Dr. Afzal is working as an associate professor and Director of Graduate Studies at the Department of Mechanical Engineering, University of New Brunswick (UNB), Canada. He is a registered Professional Engineer and a member of APEGNB. He is member of Canadian Society of Bioengineering (CSBE) and a member of American Society of Agricultural and Biological Engineers (ASABE).

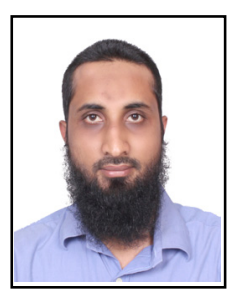

Arshad A. Salema graduated in chemical engineering from University of Pune, India in 2002. He obtained his Masters in Chemical Engineering from Universiti Teknologi Malaysia in 2007 and Ph.D. in Mechanical Engineering from same university in 2012 .

He has industrial experience of 1 year as process engineer in chemical related companies. Currently he is post-doctoral fellow in mechanical engineering department at University of New Brunswick, Canada. He has published more than 25 articles in international journals and conferences. He has also filled two patents in microwave processing of biomass. His research interest includes biomass, renewable energy, fuels and chemicals, waste processing, microwave technology, fluidized bed, thermo-chemical conversion, biocomposites, bioproducts.

$\mathrm{He}$ is life member of Indian institute of chemical engineers and senior member of APCBEES. He is also editorial advisor for International Journal of Biotechnology, Chemical \& Environmental Engineering and reviewer of more than 15 international and national journals in field of energy and biomass. 